\title{
Technological devices in treatment of diabetes mellitus
}

\author{
Cem Onur Kirac ${ }^{1}$, Suleyman Ipekci², \\ ${ }^{1}$ Department of Endocrinology, Kahramanmaraş Necip Fazll City Hospital, Kahramanmaraş, Turkey \\ ${ }^{2}$ Department of Nutrition and Dietetics, Atlas University, Faculty of Health Sciences, Istanbul, Turkey
}

\begin{abstract}
A BSTRACT
Technological inventions are being used recently to enable the treatment of diabetes mellitus more effective and easier to comply. Insulin pumps, after the implementation of readily available insulin pens, have made the transition to a very important stage in diabetes therapy. Insulin pumps have also enabled the transition from intermittent injection patterns to treatment modalities that provide continuous insulin infusion in diabetic subjects. Remedial studies on the next stage, the artificial pancreas, are still ongoing. Each of these treatments has its own advantages, some difficulties, and safety issues. We aimed to discuss the features of insulin pump devices in present short review.
\end{abstract}

Key words: Diabetes mellitus, insulin pump, therapeutics, insulin infusion systems, technological devices.

$\triangle$ Assoc. Prof. Dr. Suleyman Ipekci

Department of Nutrition and Dietetics Atlas University, Faculty of Health Sciences, Istanbul, Turkey

Email: sipekci@gmail.com

Received: 2021-05-26/Accepted: 2021-05-31

Published online: 2021-06-01

\section{Introduction}

Insulin therapy is needed to ensure glycemic control in all patients with Type 1 diabetes mellitus (DM) and many Type 2 DM patients, and daily multiple-dose insulin treatment is usually required in the later stages of the disease [1]. Daily multiple dose insulin treatment is a difficult regimen to apply for certain diabetic subjects, thus well glycemic control cannot be achieved in these individuals [2]. The idea of providing continuous insulin infusion via an insulin pump has emerged in order to provide treatment compliance and better blood glucose control. The first insulin pump was tested on patients with Type 1 DM in 1976, and researchers were concluded that this treatment could provide physiological glucose concentration in blood of the diabetic patients [3]. While the insulin pumps produced at that time were the size of a backpack, their size was reduced to the size of a cell phone currently. Insulin pump has become a much more frequently and effectively used treatment option in diabetes mellitus during last 35 years, the method owing to the developing computer technologies and new analog insulins [4]. The rate of insulin pump use as a treatment modality varies from country to country which depends on the differences in health and insurance systems. While about $64 \%$ of Type 1 DM patients in the United States treated with an insulin pump [5], this rate rises to $70-93 \%$ in certain centers in Europe [6]. These rates are predicted to increase in the future as technological advances in diabetes therapy evolve in the following years.

\section{Types of insulin pumps}

Patch and micro insulin pumps: These pumps are smaller in size than conventional insulin 
pumps. It consists of two parts; the first part is both electronic and mechanical part, which is the insulin reservoir connected to the skin with a short cannula, and the other is the electronic part that enables the control of insulin release with a wireless connection [7]. While some of this pump type provides bolus therapy in addition to the programmed basal insulin infusion, some of them, which are frequently used for Type 2 DM patients, do not allow a programmable basal infusion release, and give fixed bolus doses [8]. There are contradictory results in studies on this type of insulin pumps. In addition to studies showing that there was no difference in HbA1c levels when using different types of pumps in patients using daily multi-dose insulin therapy [9], other studies observed a significant improvement in HbA1c levels and a decrease in the required daily insulin dose and the rate of hypoglycemia after switching the treatment to the patch insulin pump [10].

Sensor integrated insulin pumps: While there is no increased risk of hypoglycemia in many studies in adult patients using insulin pumps, there are studies showing that the risk of hypoglycemia increases in the pediatric age group [11]. Based on this, the idea of integrating a continuous glucose monitoring system into insulin pumps has emerged. When these devices detect hypoglycemia, they automatically stop insulin infusion. It has been shown that a better glycemic control is provided with less risk of hypoglycemia with this type of insulin pump [12]. While it reduces the risk of hypoglycemia, it does not protect against hyperglycemia, hence this is the disadvantage of this type of insulin pumps. Therefore, the idea of an artificial pancreas has been put forward.

Dual hormone closed loop system (Artificial pancreas): Glucagon is released from pancreatic alpha cells in response to hypoglycemia in healthy individuals. This protective mechanism may not be activated in patients with type $1 \mathrm{DM}$ and susceptibility to hypoglycemia increases even in cases that insulin secretion is interrupted. Dual hormone closed-loop systems aim to better mimic this physiological process by directing both insulin and glucagon release and by releasing glucagon when hypoglycemia is occurred or predicted [13]. There are some obstacles to widely use of dual hormone systems, such as the need for a double chamber infusion pump and the lack of stable glucagon formulations [14]. Studies on this system have shown that this system provides better glycemic control compared to the other insulin pump devices, although these studies involve small population and short-term follow up $[15,16]$.

Traditionally dual hormone approach has included the addition of glucagon, but different studies are currently testing the addition of pramlintide with insulin alone or with insulin and glucagon. Other adjunct therapies, such as glucagon-like peptide-1 and sodium glucose co-transporter- 2 inhibitors used in conjunction with advanced algorithms, also have the potential to improve postprandial glucose control compared to existing artificial pancreatic systems. Each of these therapies which recommended as addition to the closed loop systems, have their own advantages, difficulties and safety problems [17].

\section{Comparison of insulin pump and intensive insulin therapy}

The DCCT (Diabetes Control and Complications Trial) study has shown reduced micro and macrovascular complications in 1441 patients with type $1 \mathrm{DM}$ whom provided tight glycemic control by intensive insulin therapy or an insulin pump for 6.5 years, 
compared to patients received conventional therapy [18]. The EDIC (Epidemiology of Diabetes Interventions and Complications) study showed that when patients in the DCCT study were followed for diabetic complications for 30 years, tight glycemic control also reduced micro and macrovascular complications in the long term [19]. In the same period, many studies showed that frequent and severe hypoglycemia increased cardiovascular morbidity and mortality by causing proinflammatory, prothrombotic effects and endothelial dysfunction [20]. After studies revealed that insulin pump therapy provides better HbA1c reduction with a lower risk of hypoglycemia compared to multiple injection therapy in type $1 \mathrm{DM}$ patients, the use of insulin pumps has started to increase worldwide [10]. However, randomized controlled studies for Type 2 DM patients did not yield satisfactory results as they did in Type $1 \mathrm{DM}$ patients. In a study by Raskin et al., which included 132 patients, a similar decrease in $\mathrm{HbAlc}$ was observed in both groups when the daily multidose insulin treatment was compared with insulin pump. However, at the end of the study, $93 \%$ of the patients using insulin pumps stated that they would prefer to use an insulin pump instead of previous insulin treatments due to ease of use, comfort and flexibility in treatment [21]. In another randomized controlled study by Herman et al., in which the insulin pump and multiple insulin injection treatments were compared on 107 patients, including those aged 60 years and above, a nonsignificant decrease in HbA1c was observed. Unlike the previous study, there was no significant difference between treatment satisfaction in both groups, and at the end of that study, the HbA1c levels of both groups were below 7\%, unlike the study conducted by Raskin et al. [22]. In addition to these studies, there are reports showing that the insulin pump reduces HbA1c more effectively, but both the number of patients in these studies were less than the previous studies and the designs of the studies were different [23]. Globally, the use of insulin pumps for type 2 DM is considered in patients whose blood glucose levels were not well controlled with daily multiple dose insulin therapy.

\section{Indications of insulin pump treatment}

Inadequate glycemic control despite use of daily multiple dose insulin therapy in patients with type $1 \mathrm{DM}[24,25]$;

- Pronounced Dawn phenomenon, severe insulin sensitivity

- Frequent episodes of severe hypoglycemia or insensitivity to hypoglycemia

- Brittle diabetes (including recurrent diabetic ketoacidosis episodes)

- Patients whose lifestyle requires flexibility (shift workers, long-distance drivers, etc.)

- Patients planning pregnancy but not achieving the targeted level of glycemic control before pregnancy

For type 2 DM patients [24,25];

- Patients under insufficient glycemic control despite regular follow-up under basal-bolus therapy

- Dawn phenomenon

- Patients with severe insulin resistance (patients required 500 units of insulin daily)

\section{Contraindications of insulin pump treatment}

Regardless of the type of diabetes mellitus, patients who are thought to be unable to provide the expected glycemic control with insulin pump can be summarized as follows [24,25]; - The subjects who do not want or are not able to measure fingertip glucose 3-4 times a day. - Patients with a low level of education and low motivation to learn carbohydrate counting 
- Patients with severe psychiatric disorders (psychosis, severe anxiety, depression, etc.)

- Patients who are concerned that the use of insulin pumps may affect their lifestyle (contact sports, patients who think it will affect their sex life, etc.)

- Patients with unrealistic expectations about the insulin pump

\section{Insulin pump and pregnancy}

Insulin resistance increases as the week of gestation progresses with the effects of human placental lactogen, cortisol and prolactin. The need for insulin increases 2-3 folds as the gestational and pregestational diabetic patients approach to the end of pregnancy. These physiological changes cause a predisposition to ketosis during the fasting period (especially in the early stages of pregnancy) and to hyperglycemia during postpartum (especially in the later stages of pregnancy) [26].

The positive effect of insulin pump on glycemic control during pregnancy has not been clearly established. In a meta-analysis of 307 patients in which randomized controlled trials were evaluated, no superiority of the insulin pump over daily multi-dose insulin was observed [27]. In another retrospective study, it was reported that diabetic ketoacidosis and neonatal hypoglycemia were observed more frequently in patients using insulin pumps during pregnancy compared to the patients received daily multiple dose insulin [28]. Therefore, patients using insulin pumps during pregnancy should be warned about technical problems related to the pump, intensive training should be given to the patients and the patient should be followed closely.

\section{Complications of insulin pump}

Several complications are associated with insulin pump treatment due to mechanical failure of the pump, set or injection port. These complications have been reported at rates varying around $45 \%$ to $84 \%$ in different studies $[29,30]$. The risk of developing diabetic ketoacidosis and glycemic fluctuations increase during pump failure since insulin infusion is interrupted. Another complication is skin reactions such as infections at the infusion site, bruising and itching. In addition, lipohypertrophy may develop in the infusion area and this picture disrupts glycemic control [31]. The most important way to avoid these complications is providing adequate pump training to the patients, teaching the patient how to solve those mechanical problems, and to explain how to start subcutaneous insulin therapy in cases where the pump is failed.

\section{Conclusion}

Insulin pump would be one of the main treatment options in patients with diabetes mellitus in the near future. The use of insulin pumps will become widespread with technological advances which will reduce their complications and increase their efficiency.

Funding: The author(s) received no financial support for the research, authorship, and/or publication of this article.

Conflict of Interest: The authors declare that they have no conflict of interest.

Ethical statement: Since this research is a review study, no ethics committee decision was required.

\section{Acknowledgment}

Thank you to Associate Prof. Dr. Gulali Aktas for language and academic editing support.

\section{Open Access Statement}

This is an open access journal which means that all content is freely available without charge to the user or his/her institution under the terms of 
the Creative Commons Attribution NonCommercial License

(http://creativecommons.org/licenses/bync/4.0). Users are allowed to read, download, copy, distribute, print, search, or link to the full texts of the articles, without asking prior permission from the publisher or the author.

\section{References}

[1]Davies MJ, D’Alessio DA, Fradkin J, et al. Management of hyperglycemia in type 2 diabetes, 2018: a consensus report by the American Diabetes Association and the European Association for the Study of Diabetes. Diabetes Care. 2018;41(12):2669701.

[2]Peyrot M, Barnett AH, Meneghini LF, et al. Insulin adherence behaviours and barriers in the multinational Global Attitudes of Patients and Physicians in Insulin Therapy study. Diabet Med. 2012;29(5):682-89.

[3]Pickup JC, Keen H, Parsons JA, et al. Continuous subcutaneous insulin infusion: an approach to achieving normoglycaemia. BMJ. 1978;1(6107):204-207.

[4]Didangelos T, Iliadis F. Insulin pump therapy in adults. Diabetes Res Clin Pract. 2011;93 Suppl 1:S109-13.

[5]DeSalvo DJ, Miller KM, Hermann JM, et al. Continuous glucose monitoring and glycemic control among youthwith type 1 diabetes: international comparison from the T1D exchange and DPV initiative. Pediatr Diabetes. 2018;19(7):1271-75.

[6]McKnight JA, Wild SH, Lamb MJ, et al. Glycaemic control of type 1 diabetes in clinical practice early in the 21 st century: an international comparison. Diabet Med. 2015;32(8):1036-50.

[7]Nimri R, Nir J, Philip M. Insulin pump therapy. Am J Ther. 2020;27(1):e30-e41.
[8]Ginsberg BH. Patch Pumps for Insulin. J Diabetes Sci Technol. 2019;13(1):27-33.

[9]Leelarathna L, Roberts SA, Hindle A, et al. Comparison of different insulin pump makes under routine care conditions in adults with Type 1 diabetes. Diabet Med. 2017;34(10):1372-79.

[10]Layne JE, Parkin CG, Zisser H. Efficacy of the Omnipod Insulin Management System on Glycemic Control in Patients With Type 1 Diabetes Previously Treated With Multiple Daily Injections or Continuous Subcutaneous Insulin Infusion. J Diabetes Sci Technol. 2016;10(5):1130-35.

[11]Misso ML, Egberts KJ, Page $M$, et al. Continuous subcutaneous insulin infusion versus multiple insulin injections for type 1 diabetes mellitus. Cochrane Database Syst Rev. 2010;(1):CD005103.

[12] Bergenstal RM, Tamborlane WV, Ahmann A, et al. Effectiveness of sensor-augmented insulin-pump therapy in type 1 diabetes. $\mathrm{N}$ Engl J Med. 2010;363(4):311-20.

[13]Fuchs J, Hovorka R. Closed-loop control in insulin pumps for type-1 diabetes mellitus: safety and efficacy. Expert Rev Med Devices. 2020;17(7):707-20.

[14]Beato-Víbora PI, Arroyo-Díez FJ. New uses and formulations of glucagon for hypoglycaemia. Drugs Context. 2019;8:212599.

[15] Haidar A, Rabasa-Lhoret R, Legault L, et al. Single- and Dual-Hormone Artificial Pancreas for Overnight Glucose Control in Type 1 Diabetes. J Clin Endocrinol Metab. 2016;101(1):214-23.

[16]Blauw H, van Bon AC, Koops R, et al. Performance and safety of an integrated bihormonal artificial pancreas for fully automated glucose control at home. Diabetes Obes Metab. 2016;18(7):671-77. 
[17] Gingras V, Taleb N, Roy-Fleming A, et al. The challenges of achieving postprandial glucose control using closed-loop systems in patients with type 1 diabetes. Diabetes Obes Metab. 2018;20(2):245-56.

[18]Diabetes Control and Complications Trial Research Group, Nathan DM, Genuth S, Lachin $\mathrm{J}$, et al. The effect of intensive treatment of diabetes on the development and progression of long-term complications in insulin-dependent diabetes mellitus. N Engl J Med. 1993;329(14):977-86.

[19]Diabetes Control and Complications Trial (DCCT)/Epidemiology of Diabetes Interventions and Complications (EDIC) Study Research Group. Intensive Diabetes Treatment and Cardiovascular Outcomes in Type 1 Diabetes: The DCCT/EDIC Study 30-Year Follow-up. Diabetes Care. 2016;39(5):686-93.

[20]Calandro DA, Januszewski AS, Cuper KK, et al. Substantial and sustained HbAlc reductions in Australian insulin pump services for adults with Type 1 diabetes. Benefit also evident for older and high HbA1c subjects. Madridge J Diabetes. 2016;1:1000104.

[21]Raskin P, Bode BW, Marks JB, et al. Continuous subcutaneous insulin infusion and multiple daily injection therapy are equally effective in type 2 diabetes: a randomized, parallel-group, 24-week study. Diabetes Care 2003;26:2598-2603.

[22]Herman WH, Ilag LL, Johnson SL, et al. A clinical trial of continuous subcutaneous insulin infusion versus multiple daily injections in older adults with type 2 diabetes. Diabetes Care. 2005;28(7):156873.

[23] Bode BW. Insulin pump use in type 2 diabetes. Diabetes Technol Ther. 2010;12 Suppl 1(Suppl 1):S17-21.
[24] Grunberger G, Abelseth JM, Bailey TS, et al. Consensus Statement by the American Association of Clinical Endocrinologists/American College of Endocrinology insulin pump management task force. Endocr Pract 2014;20(5):463-89.

[25] Türkiye Endokrinoloji ve Metabolizma Hastalıkları Derneği. Diabetes mellitus ve komplikasyonlarının tanı, tedavi ve izlem k1lavuzu. 2020; 129.

[26]Bernasko J. Insulin pump therapy for pregnancy: a primer. J Matern Fetal Neonatal Med. 2012;25(5):552-57.

[27]Farrar D, Tuffnell DJ, West J. Continuous subcutaneous insulin infusion versus multiple daily injections of insulin for pregnant women with diabetes. Cochrane Database Syst Rev. 2007;(3):CD005542.

[28]Chen R, Ben-Haroush A, WeismannBrenner A, et al. Level of glycemic control and pregnancy outcome in type 1 diabetes: A comparison between multiple Daily insulin injections and continuous subcutaneous insulin infusions. Am J Obstet Gynecol. 2007;197(4):404.e1-5.

[29]Pickup JC, Yemane N, Brackenridge A, et al. Nonmetabolic complications of continuous subcutaneous insulin infusion: a patient survey. Diabetes Technol Ther. 2014;16(3):145-49.

[30]Ross P, Gray AR, Milburn J, et al. Insulin pump associated adverse events are common, but not associated with glycemic control, socio-economic status, or pump/infusion set type. Acta Diabetol 2016;53(6):991-98.

[31] Rabbone I, Minuto N, Toni S, et al. Insulin pump breakdown and infusion set failure in Italian children with type 1 diabetes: a 1-year prospective observational study with suggestions to minimize clinical impact. 
Diabetes Obes Metab. 2018;20(11):255156. 